\title{
Design History and the European Province
}

Kjetil Fallan has defined the major theme: What does "counter-geographical" design history look like? Here, I would like to formulate my responses on the subject, mostly based on my personal experience in Turkey, and with regard to the questions raised in the call for contributions.

1. What are the challenges and opportunities of writing about the design histories of the margins of Europe (and elsewhere), as opposed to the well-covered centre?

- One noticeable problem is the limited number of design documents, archives and design museums where one can find sources easily.

- The second most important problem is probably the lack of substantial research and research papers, and Masters or PhD theses to refer to due to the relative newness of design education in many countries. Undoubtedly, it takes time to launch of postgraduate programmes and produce successful research once a country has established design education.

- Because the tradition of writing histories concerning design, whether directly or indirectly, is relatively undeveloped, important literature, such as company and institution histories, biographies of well-known designers or design agents, consultancies, shops and offices, is lacking or insufficient.

- Therefore, in the absence of guiding, reliable and accepted literature, researchers may find it difficult to name and identify the key historical events, historical periods or turning points that should be accepted by those working in the same design field.

- This leads to lack of consensus on crucial and vital issues; as a corollary, researchers feel free to make their own interpretations, remarks and suggestions about significant events and dates, even though these evaluative judgements and 
proposals concerning design history are not always supported with convincing evidence.

- As a result, researchers in countries where design history is developing slowly and gradually may have a tendency of relying on foreign, internationally acknowledged writers rather than their own local sources and fellow colleagues. However, this may be a particular academic problem we encounter in Turkey that cannot be generalised. At the same time, the opposite of this attitude, i.e. only referring to national sources, is equally problematic as ignoring the international context weakens and restricts the research conducted.

2) Is Europe now becoming a province in the new world order because East Asia has taken over Britain's former role as "the workshop of the world"? How will that impact future histories of design?

- I would argue that Europe has not yet become a province in the new world order and has a potential to keep its distinct position for a while so long as new and sustainable strategies are developed. Old, established cultures have strong foundations so it takes time to weaken their powerful institutions, let alone to replace them. This is directly linked to wealth and military power.

- If East Asia can accompany economic supremacy with supremacy of new technologies and knowledge production, then it has the chance to take over Britain's role as the workshop of the world within the context of design history. This is because those who control the economy and the global market always attempt to control ideological, social and cultural realms as well. However, the UK and the rest of the old world, as the initiators of the industrial revolution, and founders of many successful design schools and courses like design business and management, undoubtedly still have several effective cards to play in the game for some time to come.

- Design histories, like all histories, are written to record, document, explain and interpret the past, to elucidate and understand the present, and to provide creative and inspirational material for forecasting the future. In politics, we observe that the official histories are written to justify the presence of the existing sovereigns, ruling classes and systems. Therefore, the formal design histories of the East will be written to reflect the situation of those countries and document, argue and justify the rise of their designs and design companies, probably in relation to and in comparison with the design events, developments and histories of the West.

- The design histories and design historiographies, mostly those that emerged in Europe and USA, will remain influential and deliver examples for young researchers in countries like China, India, Korea and Japan. Assuming that some design historians in these countries will have studied in Europe and America, the latter's influence on their education and early design writings will continue to have a crucial effect. In the West, it took more than a half a century to discuss, criticize and finally to get rid of certain impacts of the design history written by Nicolas Pevsner, who established a durable pattern for describing the 
development of design and a writing method.

- Having said that, the rise of alternative histories in the West may also pave the way for researchers who are looking for new perspectives in their work. In other words, topics such as gender studies, alternative technologies, sustainable design, social and universal design and digital humanities may provide potential design historians in East Asia with new insights and approaches. In addition, they may also come up with totally new issues particular to the region but affecting the global agenda.

3) Are there other past periods and settings where Europe has been less central to the course of events than has been portrayed in the writing of history?

- My response to this question is positive. The rise of Europe can be linked with the discoveries of the New World, Renaissance, Enlightenment and industrial revolution. Yet, earlier historical periods incorporate many surprising design marvels like Angkor Wat in Cambodia or Machu Picchu in Peru. Here we need to discuss the impact factor. Designers, designs, design processes and design ideas that they take their place in history legitimize their position through their impacts on people's ideas, works, everyday life, etc. In that sense, design without use, is useless! If a marvellous design of a remote culture is not widely known and used, it is likely that it cannot receive the amount of respect, recognition and acknowledgement that it deserves in terms of its uniqueness, and cultural and design value.

- The dilemma here is obvious: the design value of a work which secures it a role in history is reduced to its impact factor, which may independent of the design's actual quality. This reminds me of a prototype chair that I saw in a friend's house years ago. It was one of the best chairs I have ever seen but my friend never had it mass-produced because of the worry that his work would be reproduced illegally. He approached internationally known furniture producers who were interested in the chair but never reached an agreement or signed a contract. This makes me question the value of this chair despite its unarguable aesthetic and design quality because, since it has never been produced, marketed or utilized, it never existed, never had a life and disappeared before it appeared.

- In contrast, many bad designs, or designs we think are bad, are mass-produced and widely used everywhere. Think of those mostly white, plastic chairs that all look the same or similar. They are all around the world and used extensively in many places such as cheap cafes and restaurants. In contrast to my friend's chair, I believe they are subjects of the history of social and anonymous design and worth studying in depth. Ordinary plastic chairs may be considered cheap and inferior, but their ubiquitous presence in the daily life of millions of people, ascribes to them a different level of value that, I believe, a comprehensive design history cannot dare ignore. The power of the popularity of a given object, despite its poor design quality, is an issue for further debate, which is likely to rescue design history from being accused of becoming elitist and selective.

- The other important factor concerns new findings that may challenge 

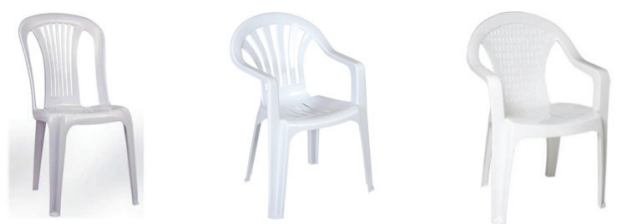

previously unquestioned parts of design history. For example, recent archaeological discoveries in Gobeklitepe in South East Anatolia are set to change radically our present knowledge and perception of prehistory. The site is dated to 10,000 BCE and probably functioned as a sanctuary furnished with huge, mysterious T shaped pillars decorated with reliefs and figures of animals, which have never been seen before for that particular era. Although design history predominantly covers more recent history and great breakthroughs may not be expected often, we should reserve space for new discoveries and their potential power to alter our perceptions of the pace of history; the history that we think we know.

- For instance, Eileen Gray's contribution to Le Corbusier's designs or Lilly Reich's significant involvement with the Barcelona Pavilion and the Brno Chair have not yet been properly credited. Perhaps we will never know who the real designers of these famous works were. One advantage that a neophyte 'provincial historian' possesses is to be aware of these blind spots in the Western history of design and to try to not to display similar failings. 